Zijie Tang, Desheng Dash Wu \& Alexandre Dolgui (2020) Option contracts for online celebrities as retailers in supply chains, International Journal of Production Research, 58:14, 4215-4232,

DOI: $\underline{10.1080 / 00207543.2019 .1650977}$

\title{
Option contracts for online celebrities as retailers in supply chains
}

\author{
Zijie Tang ${ }^{\mathrm{a}}$, Desheng Dash Wu ${ }^{\mathrm{a}, \mathrm{b} *}$ and Alexandre Dolgui $\mathbb{B}^{\mathrm{c}}$ \\ ${ }^{a}$ Economics and Management School, University of Chinese Academy of Sciences, No. 80, Zhongguancun East Road, Haidian District, \\ Beijing 100190, People's Republic of China; ' ${ }^{\text {Stockholm Business School, Stockholm University, SE-106 } 91 \text { Stockholm, Sweden; }{ }^{c} I M T}$ \\ Atlantique, LS2N, UMR-CNRS 6004, La Chantrerie, 4 rue Alfred Kastler - B.P. 20722, 44307 Nantes, France
}

(Received 4 January 2019; accepted 9 July 2019)

\begin{abstract}
The online celebrity economy, also called the internet celebrity economy, is growing rapidly in China. Celebrity retailers are usually demand sensitive and capital constrained. The capital constraints along with information asymmetry often render supply chains inefficient when manufacturers are producing at non-optimal levels. Few studies have shed light on the online celebrity supply chain, especially with respect to options. In this study, we examine how option contracts can coordinate supply chains. We find that a capital-constrained retailer can achieve more profitable orders when given an option. The manufacturer - without the full information of market demand - also benefits from offering an option to the retailer. Our numerical case shows that the options contract generates different payoffs depending on the capital of the retailer.
\end{abstract}

Keywords: online celebrity; option contract; capital constraints; information asymmetry; supply chain management

\section{Introduction}

With the ongoing development of science and technology, especially pertaining to the mobile internet, fashion products are becoming more popular. Consumers prefer fashion products recommended by fashion icons, for example, Yeezy shoes by Kanye Omari West. More and more online celebrities are affecting the preferences of young people. Phua, Lin, and Lim (2018) proved that celebrities on Instagram can influence fans' attitudes toward e-cigarettes through advertising. Unlike models, famous actors, and traditional key opinion leaders, online celebrities frequently share information about lifestyles, experiences, and opinions on their channels. To maintain their fans interest in buying products or services, online celebrities interact with fans. Online celebrity economies are composed of business chains centred on online celebrities (Xu 2017). Online celebrities are familiar with what their fans like (Djafarova and Rushworth 2017). Therefore, it makes sense for them to assume the role of retailers in supply chains. This leads to a retailer advantage because the celebrity retailers are familiar with the market demand for products. However, they are usually capital constrained. In these situations, a keen manufacturer might think about offering an option contract to attract the retailer.

Financial constraints are common in business and are associated with retailers' inventory risk (Lai, Debo, and Sycara 2009). Trade credits are widely used within supply chains to improve efficiency and service levels, and this function better than a bank loan in many cases (Kouvelis and Zhao 2012). Trade credits are especially important in underdeveloped countries, where the financial and legal systems are poor (Petersen and Rajan 1997; Fisman and Love 2003 Jacobson and Schedvin 2015). Even in many developed countries, such as France, Germany, Italy, and Sweden, trade credits can play important roles in business and in supply chains.

Information asymmetry is a prevailing phenomenon in the market. Either in commodities markets or financial markets, asymmetric information decreases the efficiency of the supply chain as well as the overall market (Balakrishnan and Koza 1993; Corbett and Tang 1999; Healy and Palepu 2001). In practice, retailers can access some private information through market research. Schweitzer and Cachon (2000), though, discovered a novel phenomenon in their research: given the demand distribution, retailers deviate from choices that maximise expected profit. This phenomenon was not consistent with prospect theory preferences. Ren and Croson (2013) shed further light on this through their overconfidence hypothesis, which explains the decision bias in the news vendor problem. Peng and Xiong (2006) found that even people with complete information could fail to make the best decision as a result of cognitive limits. Kahneman (2011) described the brain's thinking mechanism as a combination of two independent parts: one is for fast decision-making, for example when answering 'what is one plus one?'; while the other part processes questions like the Konigsberg seven-bridge problem.

*Corresponding author. Email: dash.wu@gmail.com 
Our brains evolved to work this way due to limited cognition. Online celebrities respond to their followers online, causing followers to feel like friends, and followers are then more likely to reveal their preferences (Marwick and Boyd 2011). Retailers associated with online celebrities know more about potential demand than manufacturers.

Option contracts have been widely used in supply chain management (Barnes-Schuster, Bassok, and Anupindi 2002; Wu and Kleindorfer 2005; Zhao et al. 2010). In industries for products with short life cycles (Hu, Qu, and Meng 2018), companies such as Hewlett-Packard (Nagali et al. 2008) and China Telecom (Chen, Hao, and Li 2014) have adopted this method to hedge risks across the entire supply chain (Chen, Hao, and Li 2014).

Social media hinges on social interaction, content, and communication media (Dann and Dann 2011) and is influential among people from all walks of life. How social media works in supply chains has been studied by many scholars in recent years (Deegan and Islam 2014; Chae 2015). Tuten (2013) found that using social media can influence people's behaviours, identities, and values. Many in the fashion industry recognise this and use Weibo and Facebook for advertising (Choi and Cheng 2015; Burberry annual report 2012). Scholars have introduced intermediaries such as electronic word-of-mouth to study how social media affects supply chains (Dellarocas 2003; Xu, Zeng, and He 2017; Wu and Huang 2018). However, no studies have examined online celebrities as capital-constrained retailers in supply chains. This paper explores this novel topic, analysing how online celebrities as retailers as well as option contracts affect supply chains.

We organised the paper as follows. Section 2 presents the basic setup of our models. Section 3 studies the nature of contracts in supply chains, including how option contracts help manufacturers and retailers maximise their profits. Section 4 concludes the paper. For reader convenience, several proofs can be found in the Appendix.

\section{Model formulation and assumptions}

We assume a model with one manufacturer, one retailer, and stochastic market demand. The initial demand is $D_{0}$. An option contract is set immediately after $t_{0}$.

We assume the aggregate demand $D_{t}$ follows a Geometric Brownian Motion (GBM) (Dixit and Pindyck 1994; Øksendal, Sandal, and Ubøe 2013; Kouvelis and Tian 2014) which can be defined as follows:

$$
\mathrm{d} D_{t} / D_{t}=\alpha \mathrm{d} t+\sigma \mathrm{d} z, \quad t \in(0, T]
$$

where $\alpha$ is the drift, $\sigma$ is the variance, $\sigma>0$, and $\mathrm{d} z$ is the increment of the Wiener process.

We denote the information that the manufacturer has as $I_{M}=\left(\alpha, \sigma_{i}\right), i=1,2 . I_{M}$ contains the right information on the market.

Real market demand information the retailer has is $I_{R}=(\alpha, \sigma)$. When $I_{M}=I_{r}$, it means information symmetry. We suppose that the manufacturer is capital-abundant with enough manufacturing capacity.

Firstly, the manufacturer and retailer learn the initial demand $D_{0}$ at $t=0$ through experience. They know all other information except demand volatility $(\sigma)$. Then the online celebrity retailer publicises the product and, to a certain extent, she knows the demand volatility. The manufacturer estimates volatility $\sigma_{1}$ at the probability of $\lambda_{1}, \sigma_{2}$ at the probability of $\lambda_{2}$

The manufacturer has a total cost function:

$$
T C\left(Q_{M}\right)=a+b * Q_{M},
$$

where $a$ is the fixed cost of production in this period, $b$ is the variable cost of production.

Key notation is summarised in Table 1 . Assumptions

are as follows.

(Ai) $P \geq K \geq X e^{r_{0} T-t}>m>0$

(Aii) $B_{0}, a, b, \alpha, r_{0}>0$;

(Aiii) $B_{0}$ and $\sigma$ is the private information of the retailer;

(Aiv) The manufacturer and retailer make their decision to maximise his own expected profit (rational assumption). 
The first assumption ensures products are profitable and excessive inventory leads to loss. The second ensures a common supply chain. Most online celebrities are familiar with their fans. An option contract differs from a down payment contract. It gives the retailer the right but not the obligation to buy products. Its purchase quantity is flexible, and there is no default that could potentially harm the relationship. Particularly, the manufacturer can initiate an attractive contract to maximise his profits in the presence of information asymmetry.

\begin{tabular}{ll} 
Table 1. & Key notation. \\
\hline Notation & \\
\hline$P$ & Product's price \\
$t 0$ & The start of a business period \\
$T$ & The end of a business period \\
$D_{0}$ & The initial demand at time $t_{0}$ \\
$D T$ & Demand at time T \\
$m$ & Residual value per product \\
$\pi$ & Profit of retailer \\
$E \pi n o n e$ & Expected profit of the retailer without an option contract \\
$E \pi o p$ & Expected profit of the retailer with an option contract \\
$E \pi M n o n e$ & Expected profit of the manufacturer without offering an option contract \\
$E \pi M o p$ & Expected profit of the manufacturer with offering an option contract \\
$Q$ & The quantity retailer ordered at time $t_{0}$ \\
$Q M$ & The quantity of product produced by the manufacturer \\
$X$ & Order cost per product of the retailer \\
$K$ & Price to buy a unit of product at time T \\
$B 0$ & The initial capital of retailer \\
$r 0$ & Time value of money of the retailer \\
$\alpha$ & Drift rate (growth rate) of exponential demand \\
$\sigma$ & The volatility of exponential demand \\
$\lambda_{1}$ & The manufacturer's subjective probability that volatility is $\sigma_{1}$ \\
$\lambda 2$ & The manufacturer's subjective probability that volatility is $\sigma_{2}$ \\
$N(\cdot) f$ & The distribution function of the standard normal distribution \\
$(D T)$ & The density function of total demand at time T \\
$a$ & The fixed cost of production \\
$b$ & The variable cost of production \\
\hline
\end{tabular}

\section{Models with information asymmetry and capital constraints}

In this section, we first study how an option contract improves the retailer's profit when it is faced with constrained capital. Secondly, we study how it helps the manufacturer schedule optimal production. At the end of this section, we present a numeric example to show how an option contract coordinates the supply chain.

\subsection{The retailer's problem}

We start our analysis from the perspective of the retailer.

\subsubsection{Profit without option contract}

The profit of a retailer without an option contract is as follows:

Profit $=$ Future Revenue $*$ Discount rate - Total Cost

where

Future Revenue $=$ Sales $* P+$ Total residual value $=\operatorname{Min}\left(\mathrm{Q}, D_{t}\right) * P+\operatorname{Max}\left(0, Q-D_{t}\right) * m$, Discount rate $=e-r(T-t)$, TotalCost $=Q * X$. 
The expected profit of the retailer without an option contract is

$$
\begin{aligned}
& \left.\alpha, r_{0}\right)=\int^{Q}\left(P e^{-r_{0}(T-t)}-X\right) D_{T} f\left(D_{T}\right) \quad \begin{array}{ll}
E \pi_{n o n e} \\
0
\end{array}\left(Q ; t, T, P, m, X, D_{0}, \mathrm{~d} D_{T}\right. \\
& +\int_{0}^{Q}\left(m e^{-r_{0}(T-t)}-X\right)\left(Q-D_{T}\right) f\left(D_{T}\right) \mathrm{d} D_{T}+\int_{Q}^{+\infty}\left(P e^{-r_{0}(T-t)}-X\right) Q f\left(D_{T}\right) \mathrm{d} D_{T} \\
& \int_{0}^{Q}\left(P e^{-r_{0} T-t}-m e^{-r_{0} T-t}\right) D_{T} f\left(D_{T}\right) \mathrm{d} D_{T}+\int_{0}=m e-r_{0} T-t Q f(D T) \mathrm{d} D T \\
& +\int_{Q}^{+\infty}\left(P e^{-r_{0}(T-t)}\right) Q f\left(D_{T}\right) \underset{\mathrm{d} D_{T}}{-}-\int_{0}^{+\infty} Q X f\left(D_{T}\right) \mathrm{d} D_{T}
\end{aligned}
$$

where $\ln D_{t} \sim \Phi\left[\ln D_{0}+\left(\alpha-\frac{\sigma^{2}}{2}\right)(T-t), \sigma \sqrt{T-t}\right], \int_{0}^{Q}\left(P e^{-r_{0}(T-t)}-{ }_{X) D_{T}} \mathrm{f}\left(D_{T}\right) \mathrm{d} D_{T}\right.$ is the profit of sales when demand is less than $Q ; \int_{0}^{Q}\left(m e^{-r_{0}(T-t)}-X\right)\left(Q-D_{T}\right) \mathrm{f}\left(D_{T}\right)_{\mathrm{d}} D_{T}$ is the loss of redundant products; the sum of these two parts is the total profit of sales when demand is low; and $\int_{Q}^{+\infty}\left(P e^{-r_{0}(T-t)}-X\right) Q \mathrm{f}\left(D_{T}\right) \mathrm{d} D_{T}$ is the profit ceiling when demand is greater than the order quantity. If the volatility of demand is high, there may be significant missing profit.

Proposition $1 \quad$ For a retailer without an option contract, the expected profit is as follows:

$$
\text { Eпnone }=(P-m) e-r_{0} T-t[D 0 e \alpha(T-t) N(A 1)-Q N(A 2)]+\left(P e-r_{0} T-t-X\right) Q,
$$

where

$$
\begin{aligned}
& \frac{-\ln D_{0}-\alpha+\frac{\sigma^{2}}{2}(T-}{-} \\
& A_{1}=\mathrm{V}-, A_{2}=\mathrm{V}-=A_{1}+\sigma \mathrm{V} T-t . \sigma T t \\
& \sigma T t
\end{aligned}
$$

\section{Proof See Appendix A.}

Corollary $1 \quad$ The expected profit grows with the market price of the product.

To prove this, we take the partial derivative with respect to $P$.

$$
\begin{aligned}
\frac{\partial E \pi_{\text {none }}}{\partial P} & =e^{-r_{0} T-t}\left[D_{0} e^{\alpha(T-t)} N\left(A_{1}\right)-Q N\left(A_{2}\right)\right]+Q e^{-r_{0} T-} \\
& =e^{-r_{0} T-t}\left[D_{0} e^{\alpha(T-t)} N\left(A_{1}\right)-Q N\left(A_{2}\right)+Q\right] \\
& =e^{-r_{0} T-t}\left[D_{0} e^{\alpha(T-t)} N\left(A_{1}\right)+Q\left(1-N\left(A_{2}\right)\right)\right] \quad t
\end{aligned}
$$

For any $Q \geq 0, D_{0} \geq 0, \alpha, A_{1}, \sigma, T, t .\left[D_{0} e^{\alpha(T-t)} N\left(A_{1}\right)+Q\left(1-N\left(A_{2}\right)\right)\right] \geq 0, e^{-r_{0} T-t}>0$.

$$
\begin{aligned}
& \text { If } D_{0}=0 \text { and } Q=0, \underset{\partial P}{\partial E \pi_{\text {none }}}=0 \\
& \text { If }\left|D_{0}\right|+|Q| \neq 0, \frac{\partial E \pi_{\text {none }}}{\partial P}>0 \text {. This means the expected profit grows with the market price of the product. }
\end{aligned}
$$

Corollary 2 The expected profit grows with the residual value. To prove this, we take the partial derivative with respect to $m$.

$$
\frac{\partial E \pi_{\text {none }}}{\partial m}=-e^{-r_{0} T-t}\left[D_{0} e^{\alpha(T-t)} N\left(A_{1}\right)-Q N\left(A_{2}\right)\right]=\int_{0} \quad \begin{gathered}
Q \\
\left(e-r_{0} T-t\right) \cdot(Q-D T) \cdot f(D T) \mathrm{d} D T
\end{gathered}
$$


where $e^{-r_{0} T-t}>0, Q-D_{T}>0$, when $D_{T} \in[0, Q], f\left(D_{T}\right)$ is the density function of total demand. $\int_{0}^{Q}\left(e^{-r_{0} T-t}\right) \cdot\left(Q-D_{T}\right) \cdot f\left(D_{T}\right) \mathrm{d} D_{T}$ is strictly positive when $Q>0$. This means the expected profit grows with the residual value.

Corollary 3 The expected profit decreases with order cost.

To prove this, we take the partial derivative with respect to $X$.

$$
\begin{aligned}
\frac{\partial E \pi_{\text {none }}}{\partial X} & =\int_{0}^{Q}-X \cdot D_{T} \cdot f\left(D_{T}\right)_{\mathrm{d} D_{T}}-\int_{0}^{Q} X \cdot\left(Q-D_{T}\right) \cdot f\left(D_{T}\right)_{\mathrm{d} D_{T}}-\int_{Q}^{+\infty} X \cdot Q f\left(D_{T}\right) \mathrm{d} D_{T} \\
& =-\int_{0}^{+\infty} X \cdot Q f\left(D_{T}\right)_{\mathrm{d} D_{T}<0 .}
\end{aligned}
$$

This means the expected profit decreases with order cost.

Corollary $4 \quad$ The expected profit increases with initial demand.

To prove this, we take the partial derivative with respect to $D_{0}$.

$$
\frac{\partial E \pi_{\text {none }}}{\partial D_{0}}=(P-m) e^{\left(\alpha-r_{0}\right) T-t} N\left(A_{1}\right) \text {, based on Assumption }(A i) \text {, it is strictly positive, which means the expected profit }
$$

increases with initial demand.

Proof See Appendix A

Corollary 5 The expected profit grows with the drift rate of demand. To

prove this, we take the partial derivative with respect to $\alpha$.

$\underline{\partial E \pi^{n o n e}}$

да is strictly positive based on our Assumptions. This means the expected profit of the retailer without an option contract grows with the growth rate of demand.

Proof See Appendix A

Similarly, we can prove that $\frac{\partial E \pi_{n o n e}}{\partial r_{0}}<_{0}$. This indicates if the time value of money (opportunity cost) of the retailer is higher, the expected profit's present value is lower.

\subsubsection{Profit with an option contract}

The profit of a retailer with an option contract is

$$
\text { Profit }=\text { Future Revenue } * \text { Discount rate }- \text { Total Cost }
$$

where

$$
\begin{aligned}
& \text { Future Revenue }=\text { Sales } * P+\text { Total residual value }=D_{t} * P+\operatorname{Max}\left(0, Q-D_{t}\right) * m, \text { Discount rate }=e^{-r_{0}(T-t)}, \\
& \text { Total Cost }=Q * X+\operatorname{Max}\left(0, D_{t}-Q\right) * K * e^{-r_{0}(T-t)}
\end{aligned}
$$

The expected profit of the retailer without an option contract is

$$
\begin{aligned}
E \pi_{o p}\left(Q ; t, T, P, m, X, D_{0}, \alpha, r_{0}, K\right) & \int_{0}^{Q}(P-m) e^{-r_{0} T-t} D_{T} f\left(D_{T}\right) \mathrm{d} D_{T}+\int_{0}=Q\left(m e^{-r_{0} T-t}-X\right) f\left(D_{T}\right) \mathrm{d} D_{T} \\
& +\int_{Q}^{+\infty}(P-K) \cdot e^{-r_{0} T-t} D_{T} f\left(D_{T}\right) \mathrm{d} D_{T}+\int_{Q}^{+\infty}(K Q e^{-r_{0} T-t}-\underbrace{}_{Q}{ }^{+\infty} f\left(D_{T}\right) \mathrm{d} D_{T},
\end{aligned}
$$


where

$$
\ln D_{t} \sim \Phi\left[\ln D_{0}+\left(\alpha-\frac{\sigma^{2}}{2}\right)(T-t), \sigma \sqrt{T-t}\right]
$$

Proposition 2 For a retailer who is given an option contract, the expected profit of her is as follows:

$$
\left.E^{\pi_{o p}}=D_{0} e^{\left(\alpha-r_{0}\right) T-t}\left[P-K+(K-m) N\left(A_{1}\right)\right]+Q\left[(m-K) e^{-r_{0} T-t}\right] N\left(A_{2}\right)\right]+Q\left(K e^{-r_{0} T-t}-X\right)
$$

where

$$
\begin{array}{ll}
\frac{-\ln D_{0}-\alpha+\frac{\sigma^{2}}{2}(T-}{-} & \\
A_{1}=\mathrm{V}-, A_{2}=\mathrm{V}-=A_{1}+\sigma \mathrm{V} T-t . \sigma T t & \sigma T t
\end{array}
$$

Proof See Appendix A

Corollary $6 \quad$ The expected profit grows with the market price of the product.

To prove this, we take the partial derivative with respect to $P$.

$$
\begin{aligned}
\frac{\partial E \pi_{o p}}{\partial P} & =\int_{0}^{Q} e^{-r_{0} T-} \quad \begin{array}{ll}
t D f \\
T & T) \mathrm{d} D T e
\end{array}+\int^{+\infty} \quad\left(D-r_{0} T-t D T f(D T) \mathrm{d} D T\right. \\
& =D 0 e\left(\alpha-r_{0}\right)(T-t)>0 .
\end{aligned}
$$

This means the expected profit grows with the market price of the product.

Corollary $7 \quad$ The expected profit grows with the residual value. To

prove this, we take the partial derivative with respect to $m$.

$$
\begin{aligned}
\underline{\partial E \pi}{ }^{o p}= & \int^{Q}\left(Q-D_{T}\right) e^{-r_{0} T-t} f\left(D_{T}\right) \\
0 \quad & +Q e^{-r_{0} T-t} N\left(A_{2}\right) . \quad \mathrm{d} D_{T}=-D_{0} e\left(\alpha-r_{0}\right)(T-t) N\left(A_{1}\right)
\end{aligned}
$$

In the expression, $e^{-r_{0} T-t}>0, Q-D_{T}>0$ when $D_{T} \in[0, Q], f\left(D_{T}\right)$ is the density function of total demand.

$\int_{0}^{Q}\left(e^{-r_{0} T-t}\right) \cdot\left(Q-\quad D_{T}\right) \cdot f\left(D_{T}\right) \mathrm{d} D_{T}$ is strictly positive when $Q>0$. This means the expected profit grows with the residual value.

Corollary $8 \quad$ The expected profit decreases with order cost.

To prove this, we take the partial derivative with respect to $X$.

$$
\frac{\partial E \pi_{o p}}{\partial X}=\int_{0}^{Q}-Q f\left(D_{T}\right)_{\mathrm{d} D_{T}}+\int_{Q}^{+\infty}-Q f\left(D_{T}\right) \mathrm{d} D_{T}=-Q<0 .
$$

This means the expected profit decreases with order cost.

Corollary $9 \quad$ The expected profit increases with initial demand.

To prove this, we take the partial derivative with respect to $D_{0}$. 


$$
\frac{\partial E \pi_{o p}}{\partial D_{0}}=(P-m) e^{\left(\alpha-r_{0}\right) T-t} N\left(A_{1}\right) . \text { Based on Assumption (Ai), it is strictly positive, which means the expected profit }
$$

decreases with initial demand.

Proof See Appendix A

Corollary $10 \quad$ The expected profit grows with the drift rate of demand. To prove this, we take the partial derivative with respect to $\alpha$.

$\partial E \pi_{o p}$

da is strictly positive based on our Assumptions. This means the expected profit of the retailer with an option contract grows with the growth rate of demand.

Proof See Appendix A

Corollary 11 The expected profit decreases with the opportunity cost. To prove this, we take the partial derivative with respect to $r_{0}$.

$$
\frac{\partial E \pi_{o p}}{\partial r_{0}}=-T-t D_{0} e^{\left(\alpha-r_{0}\right) T-t}\left[P-K+(K-m) N\left(A_{1}\right)\right]-T-t_{t Q K e-r_{0} T-t}(1-N(A 2))-T-t Q m e-r_{0} T-t N(A 2),
$$

where all three terms above are obviously negative, their sum is also negative. This means the real expected profit decreases with $r_{0}$ (the opportunity cost of retailer's money).

Corollary 12 (a) The expected profit decreases with the option's exercise cost.

Table 2. A brief conclusion of the relationship between

\begin{tabular}{|c|c|c|}
\hline & Eாnone & Eॉ $о p$ \\
\hline$P$ & + & \\
\hline$M$ & + & + \\
\hline$X$ & - & + \\
\hline$D_{0}$ & + & -+ \\
\hline$\alpha$ & + & + \\
\hline$r 0$ & - & - \\
\hline
\end{tabular}
expected profit and parameters.

To prove this, we take the partial derivative with respect to $K$.

$$
\begin{aligned}
& {\overline{\partial E \pi_{o p}}}^{\partial \int_{0}^{Q}(P-m) e^{-r_{0} T-}{ }_{t} D_{T f}\left(D_{T}\right) \mathrm{d} D_{T}+\int_{0}^{Q} Q\left(m e^{-r_{0} T-t}-X\right) f\left(D_{T}\right)_{\mathrm{d} D T}} \\
& \partial K \\
& +\frac{\int_{Q}^{+\infty}(P-K) \cdot e^{-r_{0} T-}}{{ }_{t} D_{T f}}\left(D_{T}\right) \mathrm{d} D_{T}+\int_{Q}^{+\infty}\left(K Q e^{-r 0 T-t-X Q) f\left(D_{T}\right) \mathrm{d} D_{T}}\right. \\
& \partial K=\int_{Q}^{+\infty}\left(Q-D_{D T}\right) e-r 0 T-t f
\end{aligned}
$$

$(D T) \mathrm{d} D T<0$,

which means when $K$ becomes higher, the expected profit decreases.

(b) When $K=X e^{r_{0} T-t}$, the retailer chooses to order $Q=0$, no matter what the other parameters are. This is because the retailer will choose to buy products at $t=T$, and the present value of $K$ is $K e^{-r} T-t=X$, which is the cost of making an order at $t=t$. Deciding at $t=T$, the retailer can avoid any demand uncertainty without extra cost. 
If there are no implicit costs (losing good will, for example), when ${ }^{K}=\lim _{\varepsilon \rightarrow 0_{+}} P+\varepsilon$ or greater, the retailer will choose not to activate the contract. This is because every single product sold will bring a loss.

Only when $X e^{r_{0} T-t} \leq K \leq P$, the contract makes sense (Table 2).

Generally, the expected profits of retailers with or without the contract share the same characteristics. The trend is the same, but there are some subtle differences. Next, we thoroughly study how this contract helps support the supply chain.

\subsubsection{Optimal order quantity of the retailer}

We have already proved Equations (4) and (6). For the retailer, an optimal order quantity is that which can maximise her expected profit. In this section, we will present an analytic solution of the optimal order quantity with and without an option contract.

The optimal order quantity must satisfy two conditions. First, the first-order partial derivative must be zero. Second, the second-order partial derivative needs to be negative. The retailer may not be able to use an optimal ordering strategy because of capital constraints.

Proposition $3 \quad$ The retailer without an option contract has a theoretical optimal-order quantity:

$$
Q * \text { none }=D_{0} e^{N^{-1}\left[\frac{p-X e^{r_{0} T-t}}{p-m}\right] \sigma \sqrt{T-t}+\left(\alpha-\frac{\sigma^{2}}{2}\right)\left(T-{ }_{t)}\right.} \quad \text { (7) Proof } \quad \text { See Appendix A }
$$

Proposition $4 \quad$ The retailer with an option contract has a theoretical optimal-order quantity:

$$
Q^{* o p}=D_{0} e^{-1}\left[\frac{X e^{r_{0} T-t}-K}{K-m}\right] \sigma \sqrt{T-t}+\left(\alpha-\frac{\sigma^{2}}{2}\right)\left(T-{ }_{t}\right)
$$

Proof See Appendix A

Corollary 13 In any case, $Q^{*}$ op is smaller than $Q^{*}$ none. This means an option contract will help the retailer achieve the optimal order quantity.

Proof It is very easy to prove that $D_{0} e^{f 1}$ is strictly increasing with $f 1$ when $D_{0}>0$.

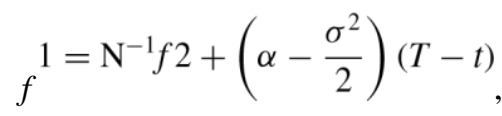

$f 1$ is strictly increasing with $f 2$.

If the manufacturer is rational, he offers an option contract at a supplement price $K$, and $K$ is usually larger than $X e^{r_{0} T-t}$, which means the order at timing $T$ should never be cheaper than at the beginning. We have assumption $\left(\right.$ Ai) $P>X e^{r_{0} T-t} \geq m$. Therefore,

$\overline{P-p X e-m r 0 T-t}>0$, and $\underline{X e r} K 0 T--m t \underline{K} \leq 0$, thus, we can deduce $Q^{*}<$ none

Corollary 14 If the value structure (ratio) of product price, order cost, and residual value are constant - in other words, $m / P$ and X/P don't change - a nominal rise in price will not affect the optimal ordering quantity. However, if the retailer is capital constrained, a nominal decrease in price is preferable for her to achieve optimal order quantity.

\subsubsection{The value of an option contract}

In part one, we demonstrate the analytic solution of the option contract in different conditions. In part two, we provide some figures to illustrate our conclusion. 
3.1.4.1. Analysis of the option value In condition ${ }_{u}: B_{0} \geq \mathrm{X} Q^{*}{ }_{n o n e}$, the retailer is not capital constrained;

In condition ${ }_{s}: \mathrm{X}^{*} Q_{o p}^{*} \leq B_{0}<X Q^{*}{ }_{n o n e}$, the retailer is slightly capital constrained; In condition $\quad a_{a}: B_{0}<X Q_{o p}^{*}$, the retailer is absolutely capital constrained.

Proposition 5 If the retailer is not capital constrained, she will make optimal orders all the time. The value of an option contract in $\quad{ }_{u}\left(V_{\mathrm{O}} \mathrm{C}_{u}\right)$ is as follows:

Proof

$$
\begin{aligned}
& =\int_{0}^{Q_{o p}^{*}}(P-m) e^{-r_{0} T-} \quad \begin{array}{c}
Q_{* o p} \\
\text { VOC } u t D T f
\end{array}+\int_{0}(D T) \mathrm{d} D T Q_{* o p}\left(m e-r_{0} T-t-X\right) f(D T) \mathrm{d} D T \\
& +\int_{Q_{o p}^{*}}^{+\infty}(P-K) e^{-r_{0} T-} \quad\left(D_{T}\right) \mathrm{d} D_{T}+\int_{Q_{o p}^{*}}^{+\infty}\left(K Q_{o p}^{*} e^{-r_{0} T-t}-{ }_{t}^{*}{ }_{o p}^{*}\right) f\left(D_{T}\right) \\
& -\int_{0}^{Q_{\text {nопе }}^{*}\left(P e^{-r_{0} T-t}-m e^{-r_{0} T-t}\right)} D_{D T}^{\text {none }}-\int_{0}^{Q^{*}}(D T) \mathrm{d} D \text { Tme-roT-t } Q * \text { nonef }(D T) \mathrm{d} D T \\
& { }^{+\infty} \quad-\int_{Q^{*}}^{+\infty}\left(P e^{-r_{0} T-t}\right) Q_{\text {none }}^{*} f\left(D_{T}\right) \mathrm{d} D_{T}+\int_{9} Q^{*}{ }_{\text {none } X f(D T) \mathrm{d} D T}
\end{aligned}
$$

Proposition 6 If the retailer is slightly capital constrained, she will order a maximal quantity ${ }^{\underline{B}}{ }^{0}{ }^{0}$ without an option, and she will order $Q^{*}{ }_{\text {p }}$ when given an option. The value of an option contract in $\quad{ }_{u}\left(V O C_{u}\right)$ is as follows: Proof

$$
\begin{aligned}
& \operatorname{VOC}_{s}=\int_{0}^{Q_{o p}^{*}}(P-m) e^{-r_{0} T-} \quad\left(D_{T}\right) \mathrm{d} D_{T}+\int_{0}{ }^{+\infty} \quad Q^{*}{ }^{*} D_{T} f \quad Q \\
& { }_{o p}^{*}\left(m e^{-r_{0} T-t}-X\right) f\left(D_{T}\right) \mathrm{d} D_{T} \\
& +\int_{Q_{o p}^{*}}^{+\infty}(P-K) e^{-r_{0} T-}+\int_{Q_{o p}^{*}}^{+\infty}\left(K Q_{o p}^{*} e^{-r_{0} T-t}-_{o p}^{*}\right) f\left(D_{T}\right) \\
& D_{T} f\left(D_{T}\right) \mathrm{d} D_{T} X Q \mathrm{~d} D_{T} \\
& B \_0 f(D T) \mathrm{d} D_{T} \\
& \left.\int P e^{-r_{0} T-t} m e^{-r_{0} T-t} \quad-{ }_{B X \underline{0}} \quad-\quad\right) D T f(D T) \mathrm{d} D T-{ }_{B \times \underline{0}} m e-r_{0} T-t
\end{aligned}
$$

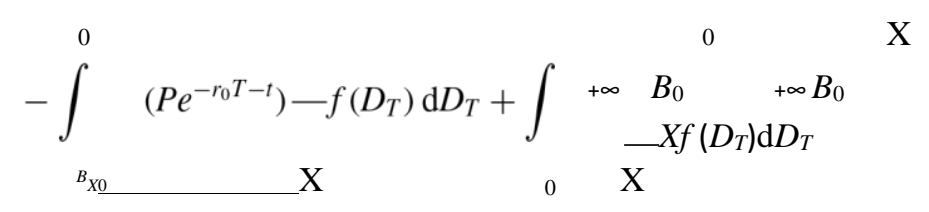




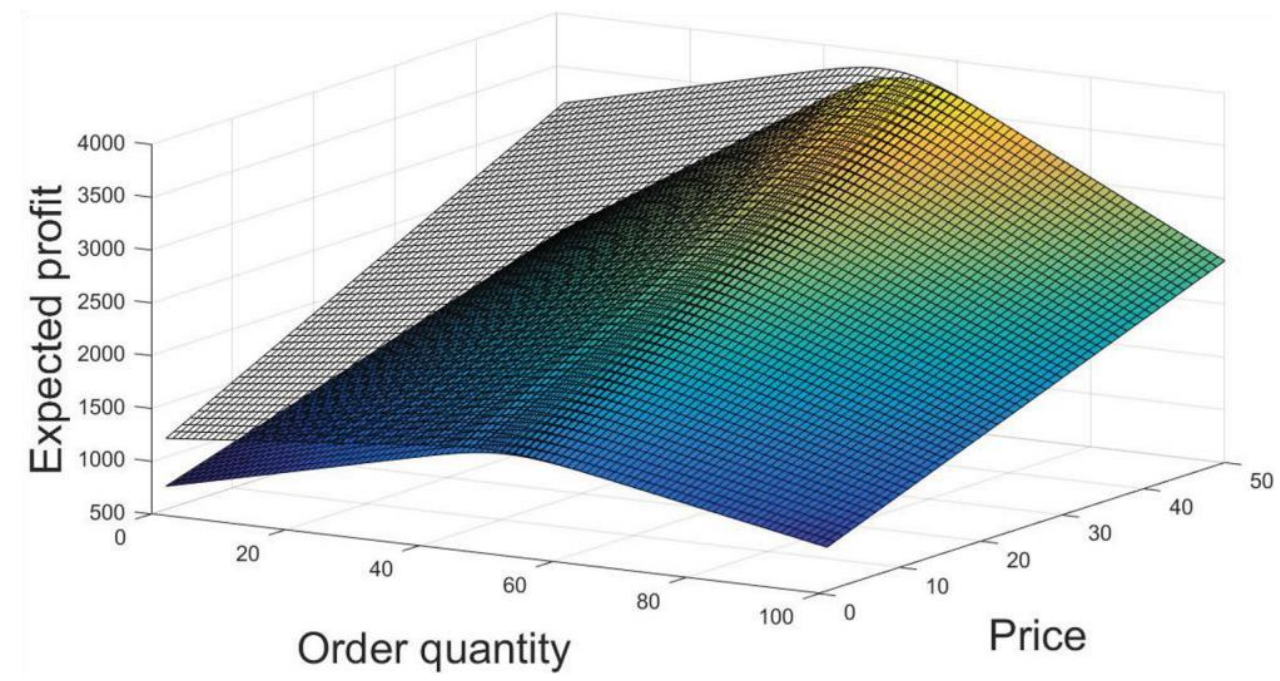

Figure 1. Price, order quantity, and profit.

Proposition 7 If the retailer is absolutely capital constrained, she will order a maximal quantity ${ }^{{ }^{0}}{ }^{0}$ all the time. The value of an option contract in $\quad$ a(VOC $\left.{ }_{\text {ua }}\right)$ is as follows:

Proof

$$
\begin{aligned}
& \int P \quad m e^{-r_{0} T-t} D f D \quad D+\int{ }_{B 0}^{B 0}{ }^{B 0} B 0 \quad{ }^{T-t} \\
& \operatorname{VOC}_{a}=\begin{array}{lllll}
x(-) & T(T) \mathrm{d} T & x & -\left(m e^{-}{ }_{0}\right. & -X) f(D T) \mathrm{d} D T
\end{array} \\
& 0 \quad 0 \quad X \\
& +\int_{\underline{\underline{B_{0}}}}^{+\infty}(P-K) e^{-r_{0} T-t} D_{T} f\left(D_{T}\right) \mathrm{d} D_{T}+\int_{\underline{X}}^{+\infty}\left(K \frac{B_{0}}{X} e^{-r_{0} T-t}-B_{0}\right)_{f\left(D_{T}\right) \mathrm{d} D_{T}} \\
& \int P e^{-r_{0} T-t} m e^{-r_{0} T-t} D f D \quad-{ }_{B \times 0}(\quad-\quad) T(T) \mathrm{d} D T-{ }_{B \times 0} m e-r_{0} T-t B
\end{aligned}
$$

$\smile_{0} f(D T) \mathrm{d} D T$

$$
\begin{gathered}
-\int_{\frac{B_{0}}{X}}^{+\infty}\left(P e^{-r_{0} T-t}\right) \frac{B_{0}}{X} f\left(D_{T}\right) \mathrm{d} D_{T}+\int_{0}^{+\infty} B_{0} f\left(D_{T}\right) \mathrm{d} D_{T} \\
=(P \\
-K) e^{-r_{0} T-t}\left[D_{0} e^{\alpha(T-t)} N\left(-H_{1}\right)-\frac{B_{0}}{X} N\left(-H_{2}\right)\right]
\end{gathered}
$$

where

$$
\begin{aligned}
& -\ln D_{0}-\alpha+\frac{\sigma^{2}}{2}\left(T-\quad=\ln \quad-\ln D_{0}-\alpha-\frac{\sigma^{2}}{2}(T-\right. \\
& \left.\left.\underline{B} \mathrm{X}_{0}-t\right) \ln \underline{\underline{B} \mathrm{X}_{0}} t\right)=\quad+ \\
& \checkmark \\
& H_{1} \vee-; H_{2}=\sqrt{ }-H_{1} \sigma T t \sigma T t \quad \sigma T t
\end{aligned}
$$

It is easy to prove that when the retailer is capital constrained, the value of an option contract grows when her initial capital decreases. In other words, the poorer the retailer is, the more valuable the option contract is. 
3.1.4.2. Comparison of expected profit In Figures 1-5, the upper transparent tier is the profit of the retailer with option contracts, the bottom is the retailer without option contracts. Figure 1 shows the expected profit of the retailer when the order quantity and price are variables.

Figure 2 shows the expected profit of the retailer when the order quantity and order cost are variables.

Figure 3 shows the expected profit of the retailer when the order quantity and residual value are variables.

Figure 4 shows the expected profit of the retailer when order quantity and length of period are variables.

Figure 5 shows the expected profit of the retailer when order quantity and exercise cost are variables.

The upper surface is the expected profit with an option contract, the lower one is expected profit without an option contract. From Figures 1-4, we can easily visualise our propositions. First, the retailer's expected profit with an option contract

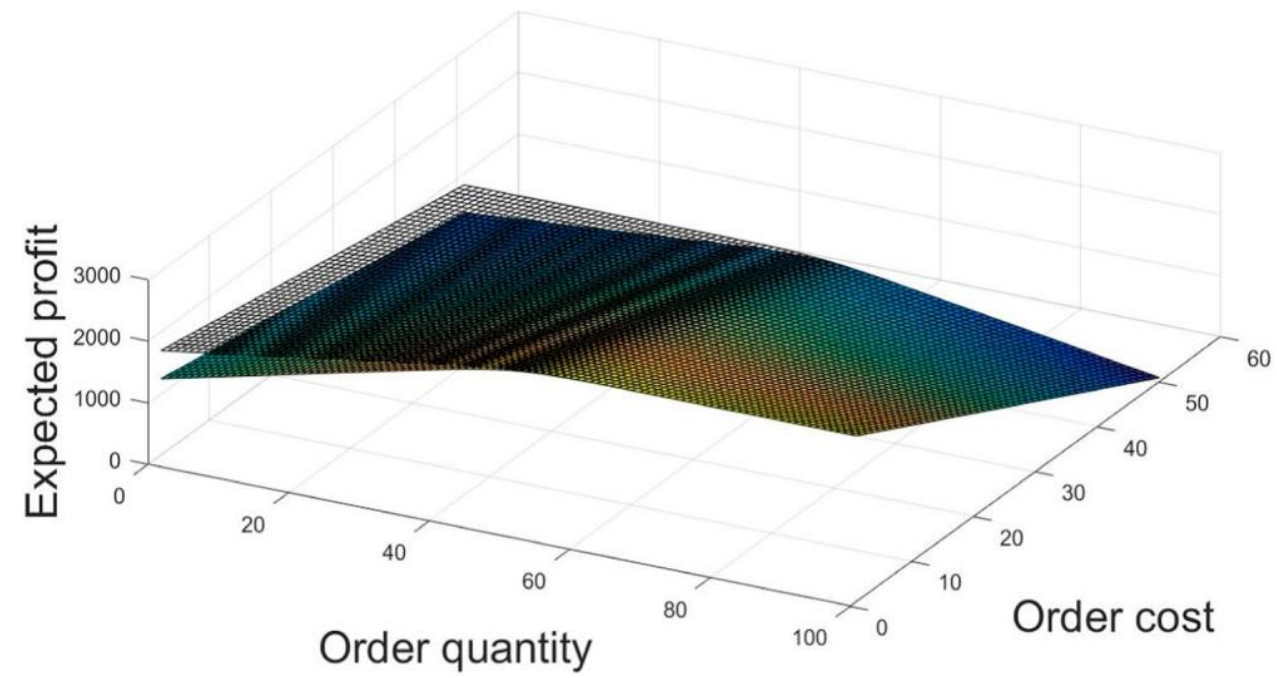

Figure 2. Order cost, order quantity, and profit.

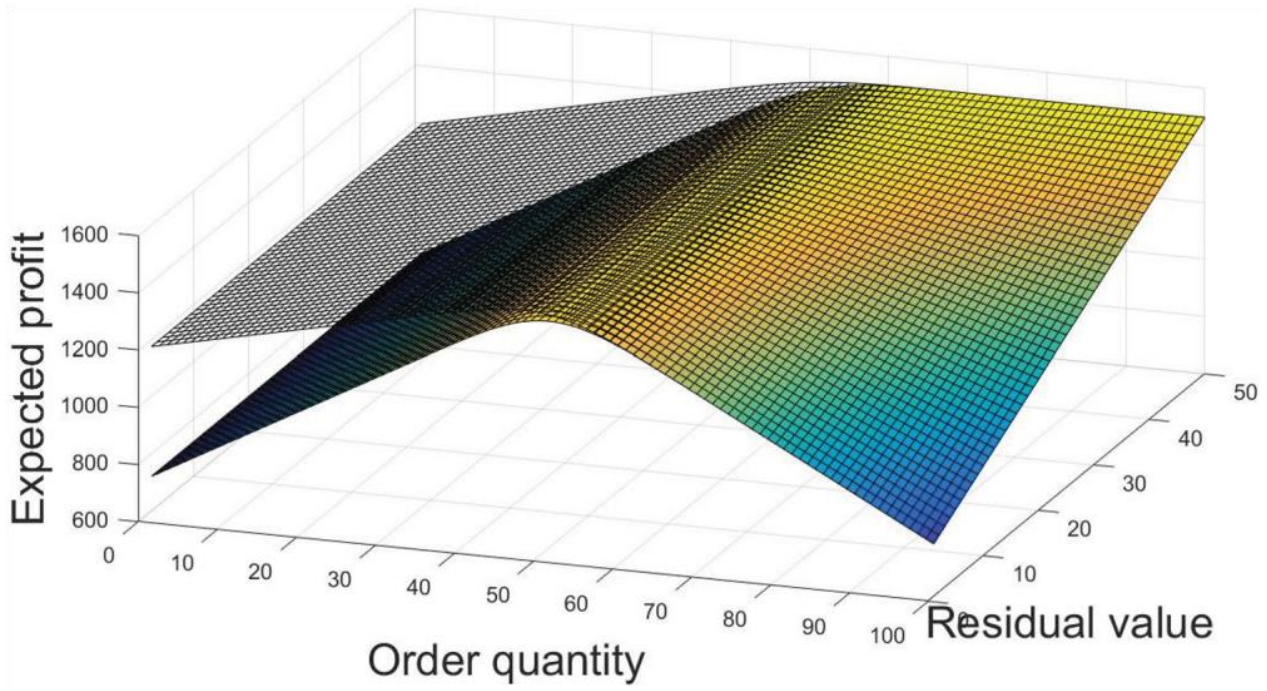

Figure 3. Residual value, order quantity, and profit.

is always larger than the profit without. Second, if the retailer is not able to order at the optimal quantity, especially when she is capital constrained, she will face a considerable profit loss (Proposition 5), and this loss has two parts: the deviation from the optimal order quantity and the missed opportunity to capture the possibility of soaring demand (Propositions 6 and 7). The first part is larger when volatility is not very high.

As we can see from Figure 5: If the exercise cost is too low, the retailer with an option contract will not make a zeroquantity order to maximise her profits (Corollary 12(b)). 


\subsubsection{Numeric examples}

In this section, we study how the option contract works in the supply chain when the retailer is capital constrained. We suppose information symmetry. As a result, there is common knowledge about the growth rate of exponential demand $(\alpha)$ and square volatility of exponential demand $\left(\sigma^{2}\right)$. The residual value $(m)$ and the time range $(T-t)$ of the product are constants. The exercise cost $(K)$ is determined at time t. The opportunity cost of the retailer's money is $r_{0}$.

Let $D_{0}=100, \alpha_{0}=0.05, \sigma^{2}=0.01, T-t=0.09, r_{0}=0.03, P=P, m=x_{1} P, X=x_{2} P, K=x_{3} P, P>K>X e^{r_{0} T-t}$ can be $0 \leq x_{1}<$ $x_{2} e^{r T-t}<x_{3} \leq 1$

Referring to (4), (6), (7), and (8) we can calculate $E \pi_{n o n e}, E \pi_{o p}, Q^{*}{ }_{n o n e}$, and $Q^{*}{ }_{o p}$.

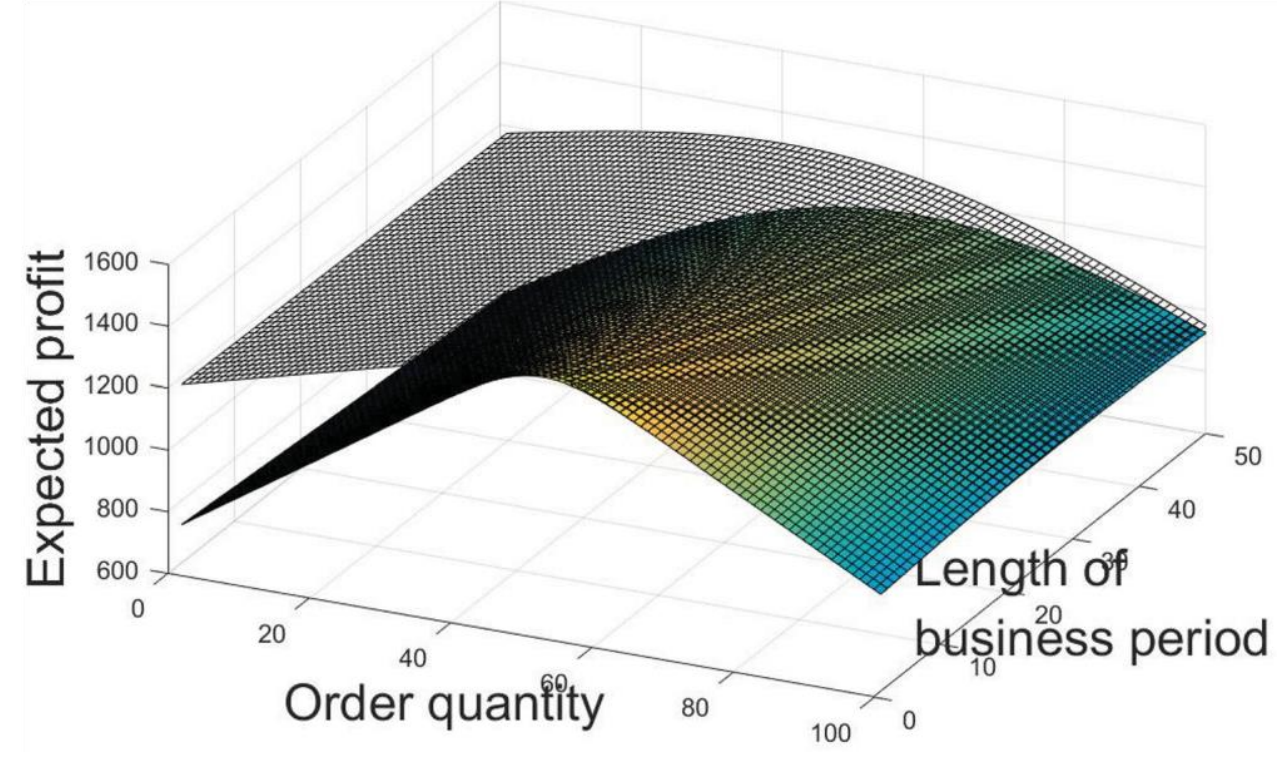

Figure 4. Period length, order quantity, and profit.

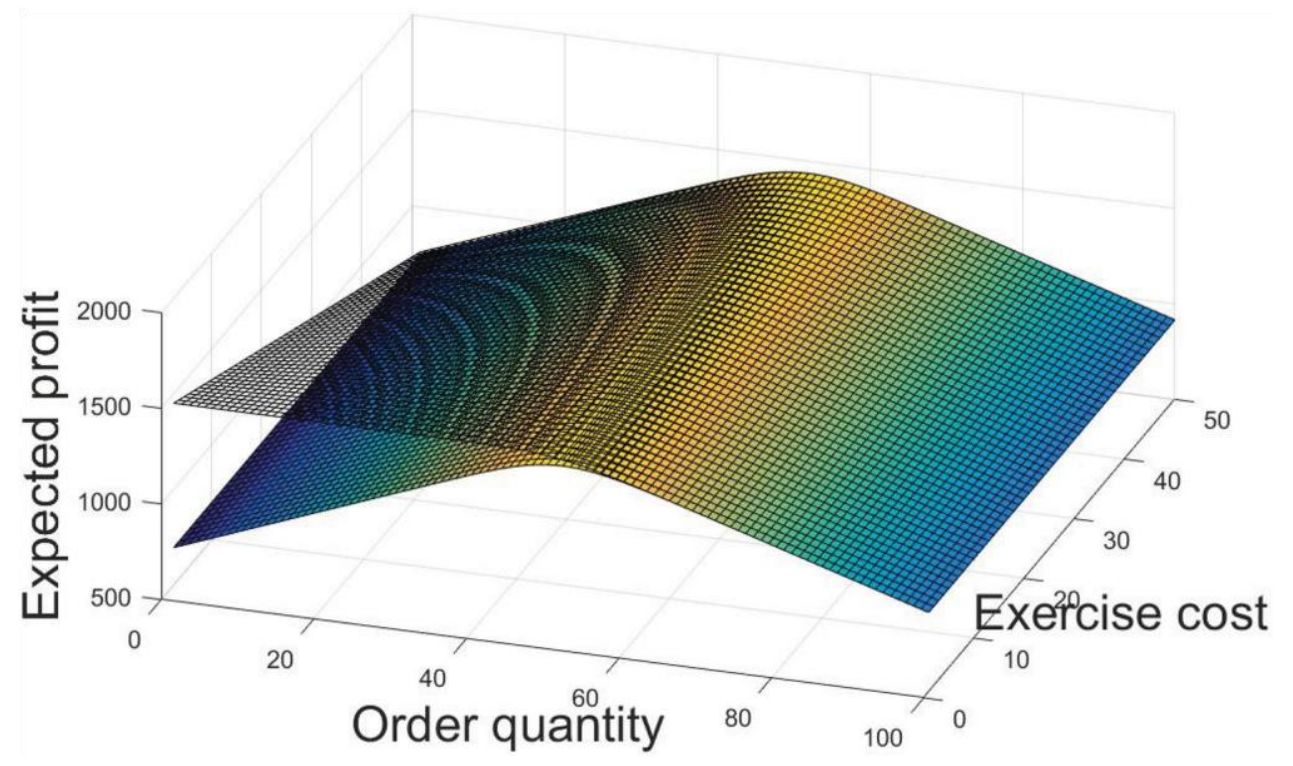

Figure 5. Exercise cost, order quantity, and profit.

We next study how $P, m, X$, and $K$ affect the optimal order quantity. When the initial capital is bounded, what happens to expected profit when there is an option contract? $x_{1}$ is the ratio of residual value, $x_{2}$ is the cost rate, and $x_{3}$ is the replenishment cost rate. 
3.1.5.1. Effect of the ratio of residual value rate $\left(\boldsymbol{x}_{1}\right)$ on the optimal order The optimal order quantity increases with the ratio of the residual value rate regardless of whether there is an option. If the distribution function of demand does not change, the residual value approaches the order cost, which means the risk of loss stemming from excess inventory decreases (Figure $6)$.

3.1.5.2. Effect of the cost rate $\left(\boldsymbol{x}_{2}\right)$ on optimal order The optimal order quantity decreases with the cost rate. This is an inverse problem of the residual value rate (Figure 7).

3.1.5.3. Effect of the exercise cost rate $\left(x_{3}\right)$ on optimal order $\quad$ See Figure 8.

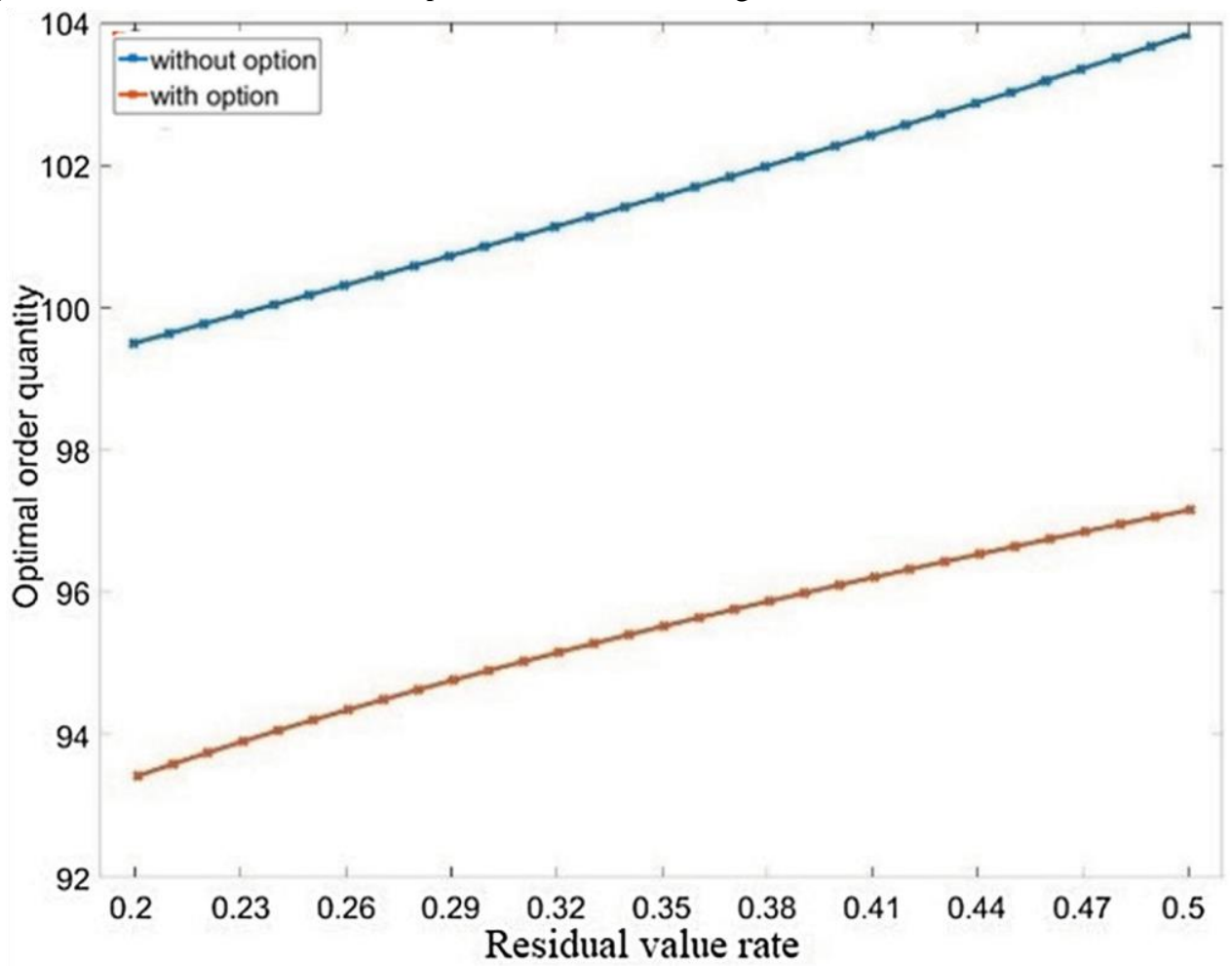

Figure 6. Effect of the ratio of the residual value rate. 


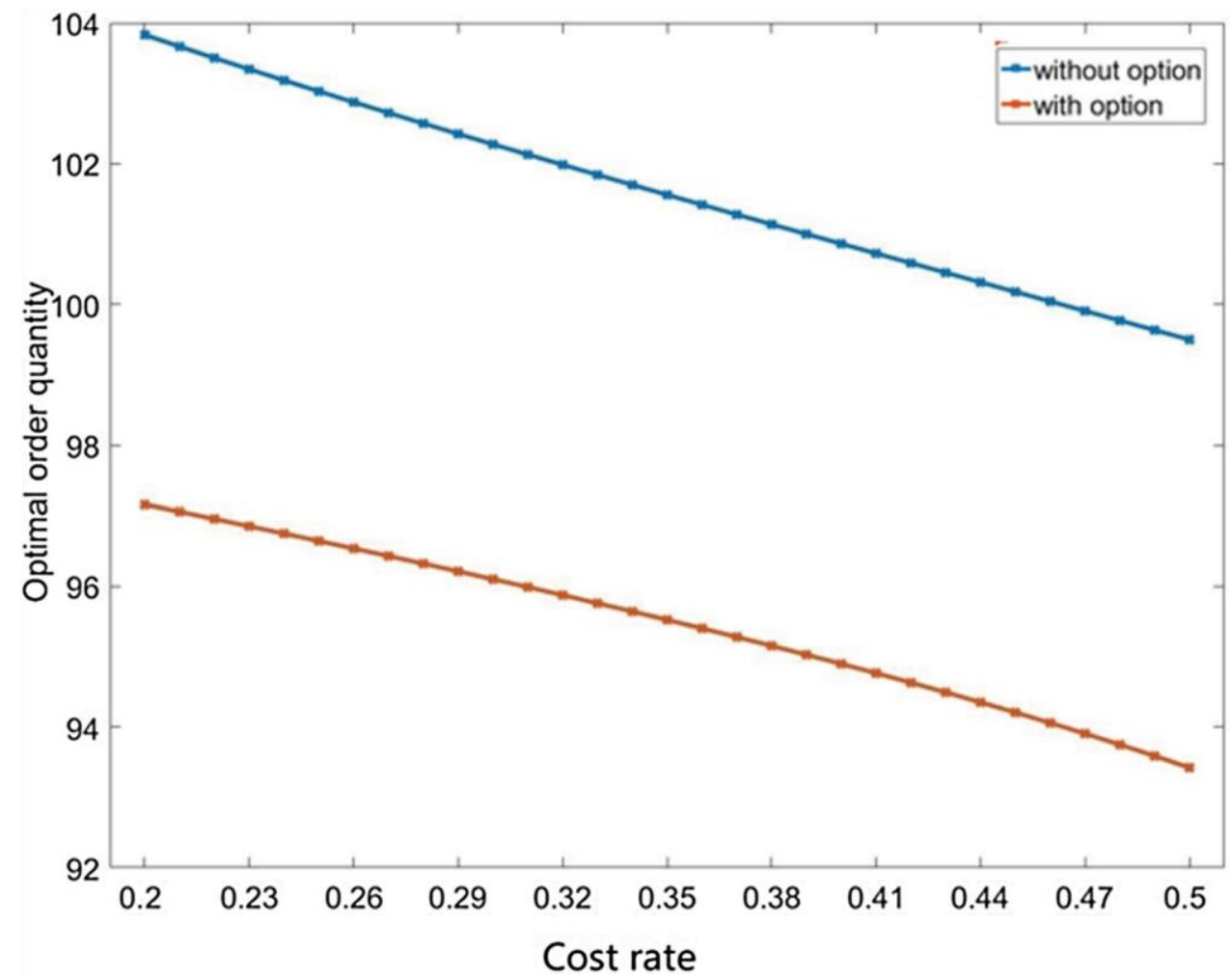

Figure 7. Effect of the cost rate.

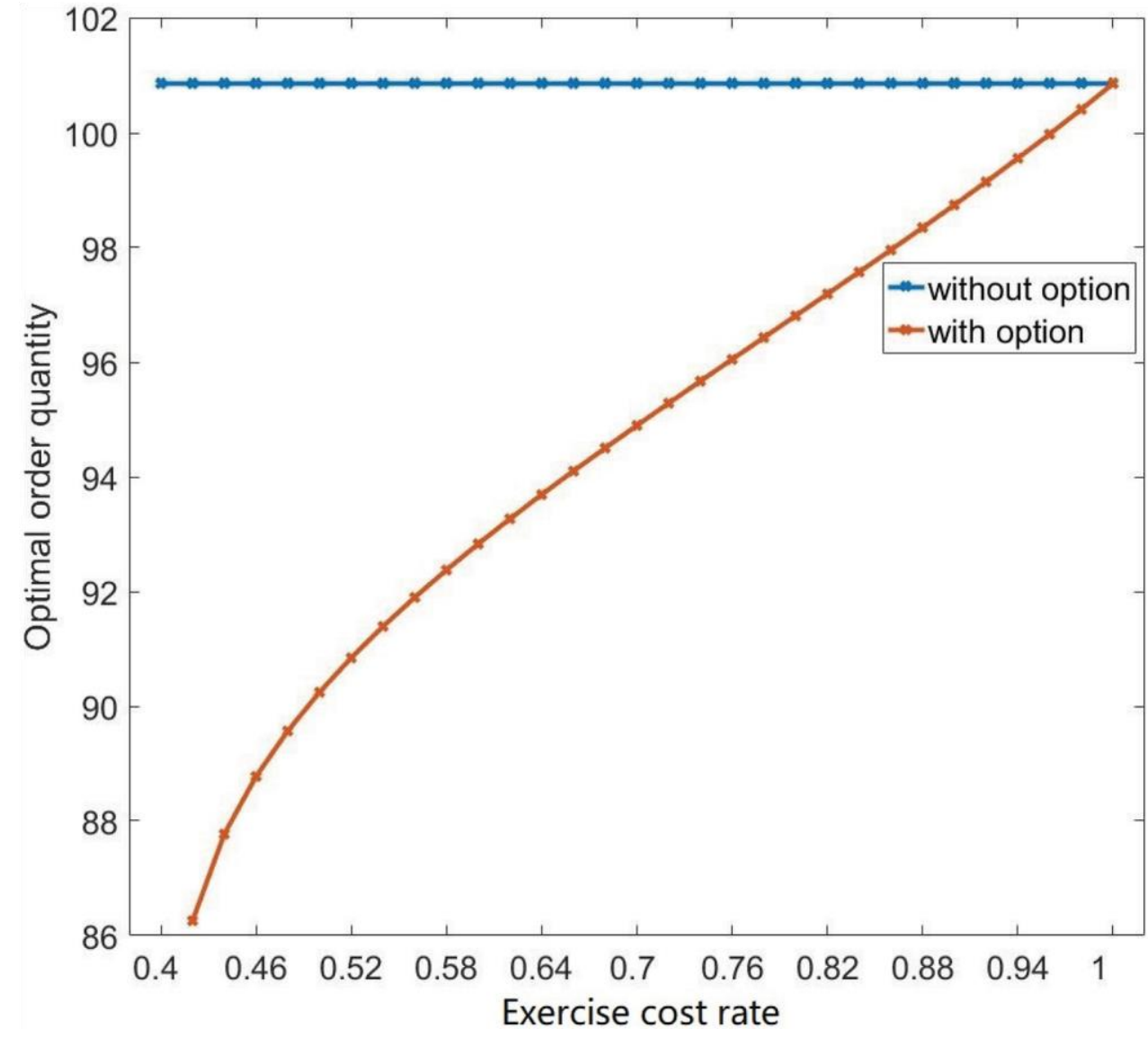

Figure 8. Effect of the exercise cost rate. 
3.1.5.4. Effect of order quantity on expected profit with constrained capital If the retailer is rational enough, she will strive to make optimal order quantity under the constraints of initial capital. When her initial capital is B1, if she is not given an option contract, she must order B1/X. In this case, she lost more than half the maximum profit. If capital is B2, she experiences a lower loss. When capital is more than B3, she will be able to make the best order (Figure 9).

If we set $P=30, x_{1}=0.1, x_{2}=0.5$, and $x_{3}=0.7$, we have the following Table 3 .

We find that an option contract is useful to improve the retailer's profit. Particularly when the retailer is capital constrained, she benefits greatly. This is very important for the manufacturer to observe and consider.

\subsection{The manufacturer's problem}

Firstly, the time period for a product is set, as a manufacturer usually arranges to source, produce, and deliver on time. Initial demand $\left(\boldsymbol{D}_{0}\right)$, the cost of money $\left(\boldsymbol{r}_{0}\right)$, the distribution type of demand, the order cost per product of retailer, the residual value per product, and the price of the product are all common knowledge. Secondly, a retailer places an order with the manufacturer that maximises her profit under the capital demand B. Thirdly, the manufacturer gets the order, however, it does not know the volatility $(\sigma)$, as a result, it cannot precisely determine the quantity that will maximise expected profit. The manufacturer can only make an estimation: $\sigma_{1}$ or $\sigma_{2}$, the subjective probability of which are $\lambda_{1}$ and $\left(1-\lambda_{1}\right)$. Next, the manufacturer will offer an option contract with exercise price $K$, and the retailer will make a new order to maximise her profit. By comparing these two orders, the manufacturer will better understand the market. Finally, the manufacturer will find an optimal level of production to maximise his profit as well.

\subsubsection{Manufacturer without an option contract}

Let $Q^{*}$ none denote the optimal order quantity of the retailer. Let $Q_{0}$ denote the quantity the retailer submits to the manufacturer. $Q_{* \text { none }}=D_{0} e^{-1}{ }^{-1}\left[\frac{p-X e^{r} 0^{T-t}}{p-m}\right] \sigma \sqrt{T-t}+\left(\alpha-\frac{\sigma^{2}}{2}\right)\left(T-{ }_{t}\right)$.

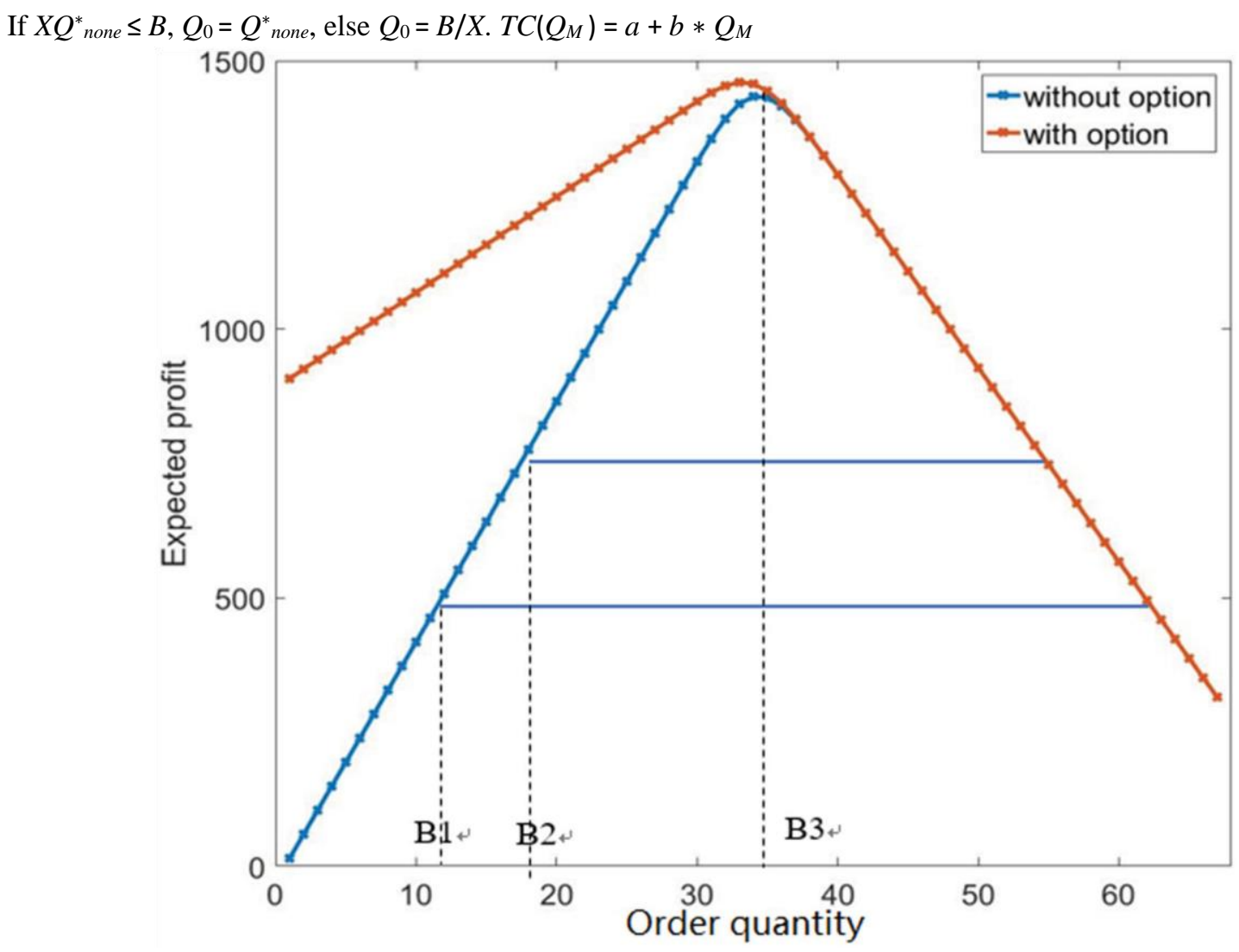

Figure 9. Effect of order quantity on expected profit. 
Table 3. Initial capital and expected profit of the retailer with and without an option contract.

\begin{tabular}{|c|c|c|c|c|c|}
\hline & & \multicolumn{2}{|c|}{ Without option contract } & \multicolumn{2}{|c|}{ With option contract } \\
\hline$\overline{Q_{*}}$ & & \multicolumn{2}{|c|}{99.499} & \multicolumn{2}{|c|}{93.422} \\
\hline Needed capital & & \multicolumn{2}{|c|}{1492.35} & \multicolumn{2}{|c|}{1401.33} \\
\hline Maximal expected $\pi *$ & & \multicolumn{2}{|c|}{1432.02} & \multicolumn{2}{|c|}{1470.87} \\
\hline \multicolumn{2}{|c|}{ Expected profit with initial capital } & $\begin{array}{c}\text { Profit } \\
E \pi_{\text {none }}\left(Q=B_{0} / 30\right)\end{array}$ & $\begin{array}{c}\text { Quantity } \\
B 0 / 30\end{array}$ & $\begin{array}{c}\text { Profit } \\
E \pi_{o p}\left(Q=B_{0} / 30\right)\end{array}$ & $\begin{array}{c}\text { Quantity } \\
B 0 / 30\end{array}$ \\
\hline & $\begin{array}{l}\leq B_{0}<1492.35 \\
1492.35 \leq B_{0}<+\infty\end{array}$ & $E \pi_{\text {none }}\left(Q=B_{0} / 30\right)$ & $2 \begin{array}{c}B 0 / 30 \\
99.499\end{array}$ & $\begin{array}{l}1470.87 \\
1470.87\end{array}$ & $\begin{array}{l}93.422 \\
93.422\end{array}$ \\
\hline
\end{tabular}

$E \pi_{M i}$ denotes the expected profit of the manufacturer when $\sigma=\sigma_{i}$, and $I=1,2$.

When there is no option contract, we assume that the retailer can make a new order at the price of $P$ (no extra profit) to avoid losing customers. The manufacturer has no need to compensate for the shortage.

Proposition $8 \quad$ For a manufacturer without an option contract, the expected profit of the manufacturer is as follows:

$$
\begin{aligned}
& \text { E } \pi \text { Mnone }=\lambda_{1} E \pi M 1 \text { none }+\left(1-\lambda_{1}\right) E \pi M 2 \text { none }
\end{aligned}
$$

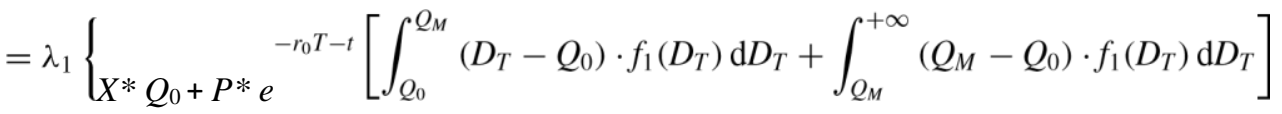

$$
\begin{aligned}
& +m^{*} e-r_{0} T-t \int_{0}^{Q_{0}}\left(Q_{M}-Q_{0}\right) \cdot f_{1}\left(D_{T}\right) \mathrm{d} D_{T}-a-b^{*} Q_{M}
\end{aligned}
$$

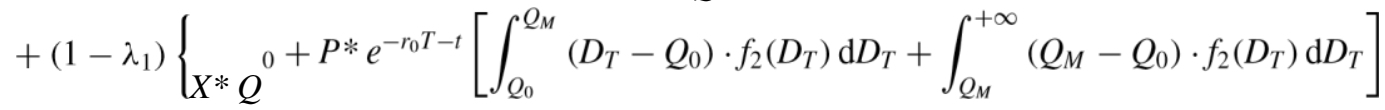

$$
\begin{aligned}
& +m^{*} e^{-r_{0} T-t} \int_{0}^{Q_{0}}\left(Q_{M}-Q_{0}\right) \cdot f_{2}\left(D_{T}\right) \mathrm{d} D_{T}-a-b^{*} Q_{M}
\end{aligned}
$$

To maximise the expected profit, the manufacturer may or may not choose to offer an option contract, depending on which is more profitable.

Proposition 9 If the manufacturer is unsure of demand volatility, he will always deviate from the optimal production and lose profit.

Proof See Appendix A

Proposition $10 \quad$ The manufacturer who does not offer an option contract has the optimal production:

$$
\begin{aligned}
& Q * \text { Mnone }=\operatorname{argmax} E \pi \text { Mnone }\left(Q_{* \text { Mnone })}\right. \\
& =\lambda_{1}\left\{X * Q_{0}+P * e^{-r_{0} T-t}\left[\int_{Q_{0}}^{Q_{\text {Mnone }}^{*}}\left(D_{T}-Q_{0}\right) \cdot f_{1}\left(D_{T}\right) \mathrm{d} D_{T}+\iint_{Q_{\text {Mnone }}^{*}}^{+\infty}\left(Q_{\text {Mnone }}^{*}-Q_{0}\right) \cdot f_{1}\left(D_{T}\right) \mathrm{d} D_{T}\right]\right. \\
& \left.\quad+m * e-r 0 T-t \int_{0}^{Q_{0}}\left(Q_{M n n e}^{*}-Q_{0}\right) \cdot f_{1}\left(D_{T}\right)_{\mathrm{d} D T}-a-b * Q_{M \text { none }}^{*}\right\}
\end{aligned}
$$




$$
\begin{aligned}
& +\left(1-\lambda_{1}\right)\left\{X * Q_{0}+P * e^{-r_{0} T-t}\left[\int_{Q_{0}}^{Q_{\text {Mnone }}^{*}}\left(D_{T}-Q_{0}\right) \cdot f_{2}\left(D_{T}\right) \mathrm{d} D_{T}+\int_{Q_{\text {Mnone }}^{*}}^{+\infty}\left(Q_{M \text { none }}^{*}-Q_{0}\right) \cdot f_{2}\left(D_{T}\right) \mathrm{d} D_{T}\right]\right. \\
& \left.+m * e-r 0 T-t \int_{0}^{Q_{0}}\left(Q_{\text {Mnone }}^{*}-Q_{0}\right) \cdot f_{2}\left(D_{T}\right)_{\mathrm{d} D T}-a-b * Q_{M \text { none }}^{*}\right\}
\end{aligned}
$$

Proof See Appendix A

\subsubsection{Manufacturer with an option contract}

The manufacturer receives an order from the retailer. However, he cannot decide how many products to produce to maximise his profit during the period because he does not know the volatility of demand, and he offers an option contract where $K=$ $K_{1}$. Given the contract, the retailer can decide whether to withdraw the previous order. If she withdraws the previous order and places a new order at $Q_{1}$, then,

$$
\begin{aligned}
& \left.\left.1=Q_{o p}^{*}=\quad-\frac{-1}{\left.\frac{K_{1}-X e_{e}^{r_{0}} T-t}{K_{1}-m}\right]}\right]_{\mathrm{N}}\right] \sqrt{T-t}+\left(\alpha-\frac{\sigma^{2}}{2}\right)(T-t) \\
& Q D_{0} e
\end{aligned}
$$

. The manufacturer will know the volatility of demand as retailer's capital. If the retailer does not withdraw the previous order, this means that $\mathrm{X} Q^{*} \stackrel{\mathrm{N}}{=} X D_{0} e$ 
their financial situation or whether they will abuse trade credit. Thus, manufacturers tend not to offer trade credit. Instead, he is more likely to offer an option contract to facilitate the partnership.

\section{Conclusion}

This article shed light on a new supply chain model that has come about because of online celebrities. We considered the option contract as a method to coordinate the supply chain and studied the characteristics of a contract. We also studied how an option contract works in the supply chain with a manufacturer with information asymmetry and a capital-constrained celebrity retailer. We prove that the knowledge of market demand is valuable for both retailer and manufacturer. When the retailer has private knowledge, she can exploit that through an option contract, while the manufacturer can also benefit from the option contract. An option contract offered by a manufacturer will increase the expected profits of the retailer. The retailer's optimal order quantity will decrease, and if she is capital constrained, it will be easier to make optimal decisions. Meanwhile, the manufacturer will design an option contract to learn more about market demand and to increase profit with less risk. Being adept at using this contract can help coordinate supply chains with capital-constrained but demand-sensitive retailers, especially with emerging online celebrities.

There are some possible extensions of this research that could make our model more realistic. For example, there could be several similar retailers in the same market, since online celebrities often imitate each other, and these behaviours complicate the understanding of demand volatility. The model could also be extended to a multi-period model, and the benefits of option contracts could be explored in this context.

\section{Disclosure statement}

No potential conflict of interest was reported by the authors.

\section{Funding}

This work is supported by the Ministry of Science and Technology of China under Grant 2016YFC0503606, by the National Natural Science Foundation of China (NSFC) for Distinguished Young Scholar (Grant 71825007), by the Chinese Academy of Sciences (CAS) Frontier Scientific Research Key Project (Grant QYZDB-SSW-SYS021), by a CAS Strategic Research and Decision Support System Development grants (Grant GHJ-ZLZX-2019-33-3).

\section{Supplemental data}

Supplemental data for this article can be accessed here https://doi.org/10.1080/00207543.2019.1650977

\section{ORCID}

Alexandre Dolgui (D) http://orcid.org/0000-0003-0527-4716

\section{References}

Balakrishnan, S., and M. P. Koza. 1993. "Information Asymmetry, Adverse Selection and Joint-Ventures.” Journal of Economic Behavior \& Organization 20 (1): 99-117.

Barnes-Schuster, D., Y. Bassok, and R. Anupindi. 2002. "Coordination and Flexibility in Supply Contracts with Options.” Manufacturing \& Service Operations Management 4 (3): 171-207.

Burberry. 2012. Annual report. http://www.burberryplc.com/investor_relations/annual_reports/financial_review. Accessed January 2, 2014.

Chae, B. K. 2015. "Insights From Hashtag\# Supply Chain and Twitter Analytics: Considering Twitter and Twitter Data for Supply Chain Practice and Research." International Journal of Production Economics 165: 247-259.

Chen, X., G. Hao, and L. Li. 2014. "Channel Coordination with a Loss-Averse Retailer and Option Contracts." International Journal of Production Economics 150: 52-57.

Choi, T. M., and T. C. E. Cheng. 2015. "Sustainable Fashion Supply Chain Management." Switzerland: Springer.

Corbett, C. J., and C. S. Tang. 1999. "Designing Supply Contracts: Contract Type and Information Asymmetry." In Quantitative Models for Supply Chain Management. Vol. 17. Boston, MA: Springer US.

Dann, S., and S. Dann. 2011. E-Marketing: Theory and Application. London: Palgrave Macmillan.

Deegan, C., and M. A. Islam. 2014. "An Exploration of NGO and Media Efforts to Influence Workplace Practices and Associated Accountability Within Global Supply Chains.” The British Accounting Review 46 (4): 397-415.

Dellarocas, C. 2003. "The Digitization of Word of Mouth: Promise and Challenges of Online Feedback Mechanisms." Social Science Electronic Publishing 49 (10): 1407-1424. 
Dixit, A. K., and R. S. Pindyck. 1994. Investment Under Uncertainty. Princeton, NJ: Princeton University Press.

Djafarova, E., and C. Rushworth. 2017. "Exploring the Credibility of Online Celebrities' Instagram Profiles in Influencing the Purchase Decisions of Young Female Users." Computers in Human Behavior 68: 1-7.

Fisman, R., and I. Love. 2003. "Trade Credit, Financial Intermediary Development, and Industry Growth.” The Journal of Finance 58 (1): 353-374.

Healy, P. M., and K. G. Palepu. 2001. "Information Asymmetry, Corporate Disclosure, and the Capital Markets: A Review of the Empirical Disclosure Literature.” Journal of Accounting and Economics 31 (1): 405-440.

Hu, B., J. Qu, and C. Meng. 2018. "Supply Chain Coordination Under Option Contracts with Joint Pricing Under Price-Dependent Demand." International Journal of Production Economics 205: 74-86.

Jacobson, T., and E. Schedvin. 2015. "Trade Credit and the Propagation of Corporate Failure: an Empirical Analysis." Econometrica 83 (4): 1315-1371.

Kahneman, D. 2011. Thinking, Fast and Slow. New York: Farrar, Straus and Giroux.

Kouvelis, P., and Z. Tian. 2014. "Flexible Capacity Investments and Product mix: Optimal Decisions and Value of Postponement Options." Production and Operations Management 23 (5): 861-876.

Kouvelis, P., and W. Zhao. 2012. "Financing the Newsvendor: Supplier vs. Bank, and the Structure of Optimal Trade Credit Contracts." Operations Research 60 (3): 566-580.

Lai, G., L. G. Debo, and K. Sycara. 2009. "Sharing Inventory Risk in Supply Chain: The Implication of Financial Constraint.” Omega 37 (4): 811-825.

Marwick, A. E., and D. Boyd. 2011. "I Tweet Honestly, I Tweet Passionately: Twitter Users, Context Collapse, and the Imagined Audience." New Media and Society 13 (1): 114-133.

Nagali, Venu, Jerry Hwang, David Sanghera, Matt Gaskins, Mark Pridgen, Tim Thurston, Patty Mackenroth, Dwight Branvold, Patrick Scholler, and Greg Shoemaker. 2008. "Procurement Risk Management (PRM) at Hewlett-Packard Company." Interfaces 38 (1): 51-60.

Øksendal, B., L. Sandal, and J. Ubøe. 2013. "Stochastic Stackelberg Equilibria with Applications to Time-Dependent Newsvendor Models." Journal of Economic Dynamics and Control 37 (7): 1284-1299.

Peng, L., and W. Xiong. 2006. "Investor Attention, Overconfidence and Category Learning." Journal of Financial Economics 80 (3): 563-602.

Petersen, M. A., and R. G. Rajan. 1997. "Trade Credit: Theories and Evidence.” Review of Financial Studies 10 (3): 661-691.

Phua, J., J. S. E. Lin, and D. J. Lim. 2018. "Understanding Consumer Engagement with Celebrity-Endorsed E-Cigarette Advertising on Instagram." Computers in Human Behavior 84: 93-102.

Ren, Y., and R. Croson. 2013. "Overconfidence in Newsvendor Orders: An Experimental Study.” Management Science 59 (11): $2502-$ 2517.

Schweitzer, M. E., and G. P. Cachon. 2000. "Decision Bias in the Newsvendor Problem with a Known Demand Distribution: Experimental Evidence.” Management Science 46 (3): 404-420.

Smith, J. K. 1987. "Trade Credit and Informational Asymmetry." The Journal of Finance 42 (4): 863-872.

Tuten, T. L. 2013. "Social Media and Consumer Behavior." The Hong Kong Polytechnic University. Accessed November 2. http://hstalks.com.ezproxy.lb.polyu.edu.hk/main/view_talk.php?t=2623\&r=703\&c=250.

Wu, J., and Q. Huang. 2018. "Myopic and Far-Sighted Pricing Strategies in a Duopoly Market with e-WOM Effect." International Journal of Electronic Commerce 22 (4): 609-630.

Wu, D. J., and P. R. Kleindorfer. 2005. "Competitive Options, Supply Contracting, and Electronic Markets.” Management Science 51 (3): 452-466.

Xu, K. 2017. "What is 'Internet Celebrity Economy' in China." Accessed April 28. http://www.targetchina.com.au/article/internetcelebrity.

$\mathrm{Xu}, \mathrm{X}$., S. Zeng, and Y. He. 2017. "The Influence of e-Services on Customer Online Purchasing Behavior Toward Remanufactured Products." International Journal of Production Economics 2017 (187): 113-125.

Zhao, Y., S. Wang, T. C. E. Cheng, X. Yang, and Z. M. Huang. 2010. "Coordination of Supply Chains by Option Contracts: A Cooperative Game Theory Approach.” European Journal of Operational Research 207 (2): 668-675. 